\title{
REVIEW
}

\section{Wnt signaling in triple-negative breast cancer}

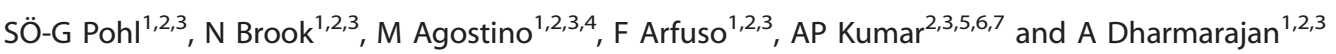

Wnt signaling regulates a variety of cellular processes, including cell fate, differentiation, proliferation and stem cell pluripotency. Aberrant Wnt signaling is a hallmark of many cancers. An aggressive subtype of breast cancer, known as triple-negative breast cancer (TNBC), demonstrates dysregulation in canonical and non-canonical Wnt signaling. In this review, we summarize regulators of canonical and non-canonical Wnt signaling, as well as Wnt signaling dysfunction that mediates the progression of TNBC. We review the complex molecular nature of TNBC and the emerging therapies that are currently under investigation for the treatment of this disease.

Oncogenesis (2017) 6, e310; doi:10.1038/oncsis.2017.14; published online 3 April 2017

\section{INTRODUCTION}

Breast cancer represents one of the most significant disease burdens of any cancer worldwide. Today, women have a one in eight chance of developing breast cancer over their lifetime, a risk that is significantly increased if they have inherited harmful mutations in BRCA1 or BRCA2. ${ }^{1}$ However, breast cancer is a complex, heterogeneous disease characterized by a great multitude of aberrations at the genomic and molecular level, which can manifest in dysregulated signaling pathways. A hallmark of many cancers is aberrant regulation of the Wnt signaling pathway, and breast cancer is no exception. ${ }^{2}$

Triple-negative breast cancer (TNBC), an aggressive subtype of breast cancer with a poor prognosis, ${ }^{3}$ is characterized by tumors that do not express estrogen receptors (ERs) or progesterone receptors (PRs), nor display an overexpression of human epidermal growth factor receptor 2 (HER2). ${ }^{4}$ Therapies targeted against HER2-positive breast cancers, such as trastuzumab (Herceptin), ${ }^{5}$ and those targeted against ER-positive breast cancers, such as tamoxifen, ${ }^{6}$ have no therapeutic benefit to individuals with the TNBC subtype. Surgical intervention and chemotherapy have been the major treatment avenues for TNBC; however, recently developed small molecules and immunotherapeutics $^{7}$ are showing promise. In this review, we will summarize the involvement of dysregulated Wnt signaling in the progression of TNBC and TNBC stem cells, as well as the emerging therapies that are currently under investigation.

\section{THE WNT SIGNALING PATHWAY}

The Wnt/ $\beta$-catenin pathway (canonical pathway)

There are currently two models of canonical Wnt/ $\beta$-catenin signaling. In the classical model, the destruction complex remains intact in the absence of Wnt stimulation (Figure 1a). Casein kinase 1 (CK1) primes $\beta$-catenin for destruction by phosphorylating Ser45, which then allows activated Glycogen synthase kinase 3 (GSK3) to phosphorylate $\beta$-catenin at Ser33, Ser37 and Thr41.8 The phosphorylated residues of $\beta$-catenin interact with the $\beta$-propeller domain of the $\mathrm{E} 3$ ubiquitin ligase $\beta-\operatorname{TrCP}$, which then ubiquitinates $\beta$-catenin, thus targeting it for proteosomal degradation. ${ }^{9}$ Wnt/ $\beta$-catenin signaling is initiated by Wnt ligands binding to a Frizzled receptor (FZD), as well as the co-receptors low-density lipoproteins 5/6 (LRP5/6). This results in activation of FZD, permitting binding of Dishevelled (Dvl) ${ }^{10}$ and phosphorylation of one or more cytoplasmic motifs of LRP5/6. A single phosphorylated motif is sufficient to activate Wnt signaling. ${ }^{11}$ Phosphorylated LRP5/6 can then interact with Axin. This interaction destabilizes the $\beta$-catenin destruction complex, which requires Axin as a scaffold and contains Dvl, the serine-threonine kinases casein kinase $1 \alpha / \beta$ (CK1), glycogen synthase kinase $3 \alpha / \beta$ (GSK3) and adenomatous polyposis coli (APC). ${ }^{12}$ Destabilizing the destruction complex prevents phosphorylation of $\beta$-catenin, which then accumulates in the cytosol before translocating to the nucleus. Once there, it binds to Transcription factor/lymphoid enhancer-binding factor (TCF/LEF) transcription factors and displaces transcriptional repressor Groucho to initiate the transcription of Wnt target genes (Figure $1 \mathrm{~b}$ ). ${ }^{13}$ In the new model, ${ }^{14-16}$ the destruction complex is stabilized by Axin in both the presence and absence (Figure 1c) of Wnt activation, and $\beta$-catenin is degraded through phosphorylation-mediated recognition by $\beta$-TrCP in the intact complex. This allows newly synthesized $\beta$-catenin to accumulate in the cytosol before nuclear translocation (Figure 1d). This was demonstrated through co-immunoprecipitation, whereby $\beta$-catenin phosphorylated at Ser33/Ser37/Thr41 was shown to interact with the destruction complex upon Wnt activation, which also disrupted the interaction of $\beta$-TrCP with the Axin $1-\beta$-catenin complex. ${ }^{15}$ It has also been proposed that GSK3 inhibition, and thus $\beta$-catenin translocation after Wnt activation, is mediated through the sequestration of GSK3 inside multivesicular endosomes. ${ }^{17}$ This further demonstrates the complexity of Wnt signaling.

\footnotetext{
${ }^{1}$ Stem Cell and Cancer Biology Laboratory, Perth, WA, Australia; ${ }^{2}$ School of Biomedical Sciences, Curtin University, Perth, WA, Australia; ${ }^{3}$ Curtin Health Innovation Research Institute, Curtin University, Perth, WA, Australia; ${ }^{4}$ Curtin Institute for Computation, Curtin University, Perth, WA, Australia; ${ }^{5}$ Cancer Science Institute of Singapore, National University of Singapore, Singapore, Singapore; ${ }^{6}$ Department of Pharmacology, Yong Loo Lin School of Medicine, National University of Singapore, Centre for Translational Medicine, Singapore, Singapore and ${ }^{7}$ Department of Biological Sciences, University of North Texas, Denton, TX, USA. Correspondence: Dr AP Kumar, Department of

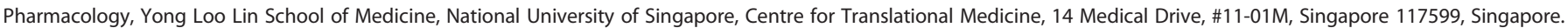
E-mail: csiapk@nus.edu.sg

or Professor A Dharmarajan, School of Biomedical Sciences, Curtin University, Kent Street, Bentley, Perth, WA 6102, Australia.

E-mail: a.dharmarajan@curtin.edu.au
}

Received 11 November 2016; revised 9 January 2017; accepted 24 January 2017 



Figure 1. Classical and new Wnt/ $\beta$-catenin pathway canonical and non-canonical pathways. (a) Overview of the 'classical' model of $W n t / \beta$-catenin signaling in OFF state with no ligand bound to FZD receptor. (b) Overview of the 'classical' model of Wnt/ $\beta$-catenin signaling pathway in ON state where Wnt ligand is bound to FZD receptor. (c) Overview of 'new' model of Wnt/ $\beta$-catenin signaling in OFF state with no ligand bound to FZD receptor. (d) Overview of the 'new' model of Wnt/ $\beta$-catenin signaling in ON state with Wnt ligand bound to FZD receptor. (e) Overview of Wnt planar cell polarity (PCP) pathway in ON state. Wnt binds multiple receptors including FZD and co-receptors ROR and Ryk. This activates Rho and Rac, which activate ROCK and c-Jun N-terminal kinase (JNK), respectively, leading to actin polymerization and regulates cytoskeletal arrangements. (f) Overview of $\mathrm{Wnt} / \mathrm{Ca}^{2+}$ pathway in $\mathrm{ON}$ state. Wnt is able to bind FZD, Ryk to initiate signal transduction, which is effected through Dvl and G proteins $(\alpha, \beta, \gamma)$. Gene transcription is induced through proteins PKC, CaMKII and Cn (Calcineurin)-activating transcription factors.

Planar cell polarity pathway

The planar cell polarity pathway (Figure 1e) is a non-canonical, $\beta$-catenin-independent pathway that regulates cellular organization and polarity, partly through cytoskeletal organization. ${ }^{18}$ Wnt ligands, such as Wnt5a, bind to FZD receptors and co-receptors, including
ROR, ${ }^{19}$ Ryk $^{20}$ and PTK. ${ }^{21}$ Dvl interacts with Rac1 ${ }^{22}$ and Dvl-associated activator of morphogenesis 1 (DAAM1). Rac1 activates c-Jun $\mathrm{N}$-terminal kinase, leading to actin polymerization, ${ }^{22}$ while DAAM1 activates Rho, which in turn activates Rho-associated kinase (ROCK) to regulate cellular cytoskeletal arrangements. ${ }^{23}$ 

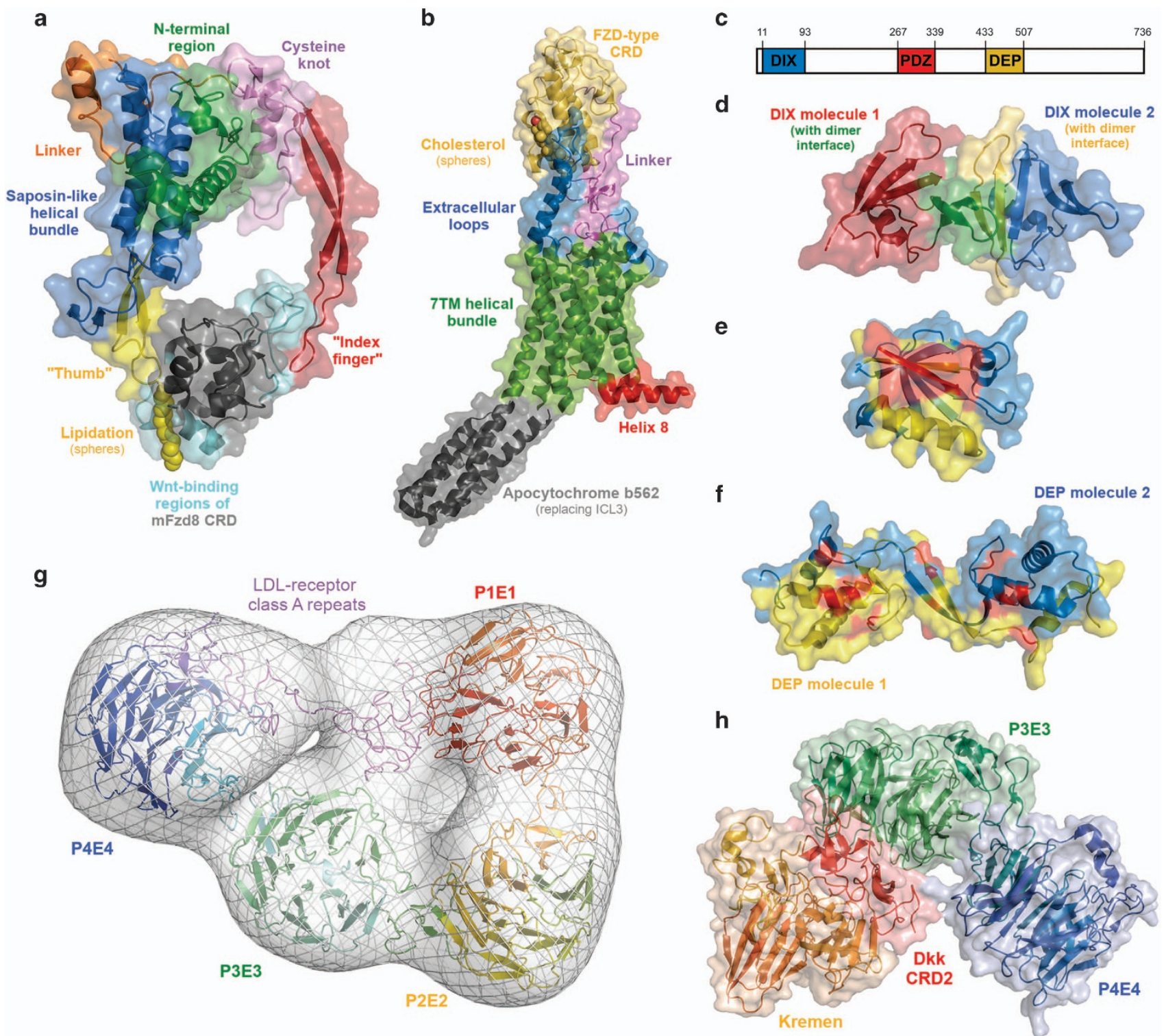

Figure 2. Molecular structures of the key Wnt signaling proteins and interactions. (a) X-ray crystal structure of the Xenopus Wnt8 complex with the mouse FZD8 cysteine-rich domain (PDB 4F0A). The key structural regions of the Wnt fold are highlighted, as are the major Wnt-interacting regions of the CRD. (b) X-ray crystal structure of the Smoothened receptor (PDB 5L7D), a Class F G protein-coupled receptor, related to FZD. The key structural regions of Smo are highlighted, as well as helix 8, which is of relevance for Dishevelled binding by FZD. (c) Schematic representation of the location of the DIX, PDZ and DEP domains within Dvl. (d) X-ray crystal structure of the DIX homodimer (PDB 4WIP). (e) X-ray crystal structure of the PDZ domain bound to a peptide (red; PDB 3CBX). The peptide-binding site is shown in yellow. (f) X-ray crystal structure of a DEP homodimer (PDB 5LNP), highlighting residues known to affect Wnt signaling (shown in red). (g) Model of the LRP6 ectodomain generated by molecular dynamics flexible fitting of the crystal structures of the P1E1-P2E2 domains (PDB 3S94) and P3E3-P4E4 domains (PDB 4AOP), and a homology model of the LDL-R type A domains (generated in Prime, based on the crystal structure of the LDL receptor ectodomain (PDB 1N7D)) to the electron microscopy structure (EMDatabank accession 1964). Gaps in the crystal structures and between the various components modeled using Prime. (h) X-ray crystal structure complex of the cysteine-rich domain 2 of Dickkopf with Kremen and the LRP6 P3E4-P4E4 domains (PDB 5FWW).

The Wnt/Ca ${ }^{2+}$ pathway

The Wnt/Ca ${ }^{2+}$ pathway (Figure $1 \mathrm{f}$ ) is activated through Wnt binding to FZD, which interacts with G proteins and Dvl. ${ }^{24}$ These interactions can activate cGMP-specific phosphodiesterase or phospholipase $C$, resulting in a release of intracellular calcium. This results in the activation of downstream signaling proteins PKC, calcineurin and CaMKII. ${ }^{25}$ CaMKII activates nuclear factor of activated T-cells, which can regulate cell adhesion and migration. ${ }^{26}$ Wnt5a induces activation of CaMKII-dependent Wnt $/ \mathrm{Ca}^{2+}$ signaling. CaMKII phosphorylates transforming growth factor $\beta$-activated kinase, which activates Nemo-like kinase. ${ }^{27}$ This cascade antagonizes canonical Wnt/ $\beta$-catenin signaling by Nemolike kinase phosphorylation of TCF4 and prevents the $\beta$-cateninTCF4 complex from binding to DNA. ${ }^{28}$

\section{Wnt ligands}

To date, 19 members of the Wnt family have been identified in mammals, all ranging between 350 and 400 amino acids in length and characterized by a conserved fold containing a conserved motif of 24 cysteine residues (Figure 2a). ${ }^{29}$ Wnt ligands are modified by lipidation, specifically, the addition of a palmitoleyl group to a conserved serine by the membrane-bound 
O-acyltransferase Porcupine. ${ }^{30}$ Wnt lipidation is crucial for secretion from the endoplasmic reticulum ${ }^{31}$ and essential for Wnt function. Wnt lipidation was initially suggested to occur at Cys77 of Wnt3a (cysteine 3 of the Wnt fold); ${ }^{32}$ however, lipidation at this cysteine has been conclusively disproven by crystallographic, ${ }^{33}$ mutational $^{31}$ and imaging studies. ${ }^{30}$

\section{FZD receptors}

FZD receptors are a group of 10 membrane proteins featuring an extracellular cysteine-rich domain (CRD) and a seventransmembrane domain. ${ }^{34}$ Along with the Smoothened receptor (Smo), the FZDs comprise the family of Class F G protein-coupled receptors. The crystal structure of XWnt8 in complex with the mouse FZD8 $C R D^{33}$ revealed an unusual interaction involving the direct binding of the Wnt lipid to a binding site on one side of the CRD (the 'thumb' region), as well as the binding of the region from cysteines 19 to 22 of XWnt8 to the other side of the CRD (the 'index finger' region; Figure 2a). ${ }^{35}$ Although no complete structures are available for any FZD, several structures of Smo are known, ${ }^{36-38}$ most recently including both the CRD and seven-transmembrane regions (Figure $2 b$ ), ${ }^{39}$ which are suggestive of the likely structure of FZD.

\section{Disheveled}

Three Dvl homologs are known (Dvl1/2/3), sharing high overall sequence similarity. ${ }^{40} \mathrm{Dvl}$ consists of three structurally defined domains: the DIX, PDZ and DEP domains. These three domains are separated by large insertions of unknown structure (Figure 2c); however, some functional significance has been ascribed to conserved sequences within the unstructured regions. ${ }^{41}$

Dvl polymerizes via the head-to-tail interaction of its DIX domain (Figure 2d). The DIX domain also mediates interaction with Axin. ${ }^{42}$ Mutations (V67A, K68A, Y27D) in the polymerization interface of the DIX domain strongly suppress Wnt signaling. ${ }^{43}$ The PDZ domain of Dvl (Figure 2e) interacts with a conserved motif in the FZD C-terminal (KTxxxW). ${ }^{24}$ The PDZ-FZD interaction is relatively weak, and is likely supplanted by interactions of the DEP domain with FZD. Greater insight in the role of the DEP domain in Wnt signaling was recently revealed, with this domain shown to bind as a monomer to FZD, then undergo subsequent domain swapping to assemble Wnt signalosomes. Furthermore, upon Wnt stimulation, DEP domain swapping initiates DIX-dependent Dvl and Axin polymerization, leading to the inhibition of GSK3 and Wnt signal transduction. Mutants (E499G, D460K, G436P, K438M, D449I and D452I) in the DEP domain strongly diminish Wnt signaling upon Wnt stimulation (Figure 2f). ${ }^{44,45}$ Dvl has also been shown to promote ubiquitination-mediated FZD degradation by RNF43. ${ }^{46}$ This finding suggests a dual agonist/antagonist role for Dvl in Wnt signaling.

\section{Low-density lipoprotein receptor $5 / 6$}

The extracellular domain of LRPs consists of four $\beta$-propeller repeats interspersed with epidermal growth factor repeats, followed by three LRP type A repeats (Figure $2 \mathrm{~g}$ ). ${ }^{10}$ The majority of Wnts bind to the first $\beta$-propeller/epidermal growth factor repeat (P1E1-P2E2), although Wnt3 and Wnt 3a preferentially bind to the second repeat (P3E3-P3E4). ${ }^{47}$ Wnt3 and Wnt3a binding to LRPs is competitively inhibited by Dickkopf binding to LRP (Figure 2h). ${ }^{48-50}$ The intracellular action of LRP5/6 is less clearly understood, although it is known that Wnt activation initiates phosphorylation of the intracellular PPPSPXP motifs of LRP5/6 by GSK3 and CK1, allowing the recruitment of Axin. ${ }^{51}$ Importantly, it has also been shown that without the FZD-Dvl interaction, Wnt is unable to induce phosphorylation of LRP6, reinforcing the complex interplay of proteins involved in Wnt signaling. 24,51

\section{ROR family receptor tyrosine kinases}

The ROR family of receptor tyrosine kinases consists of two evolutionarily conserved members, ROR1 and ROR2. ${ }^{52}$ The ROR ectodomains feature a FZD-type CRD most closely related to that of the skeletal muscle receptor tyrosine-protein kinase. ${ }^{53}$ ROR2 is involved in Wnt5a-mediated signaling; Wnt5a binding to ROR2 initiates ROR2 homodimerization, stimulating autophosphorylation at Tyr646. ${ }^{54}$ It has been demonstrated that Wnt5a and Wnt3a bind to ROR2; however, only Wnt5a is able to initiate the activation of the ROR2 signaling cascade. ${ }^{55}$ Recently, high expression of ROR1 has been demonstrated in TNBC cell lines,

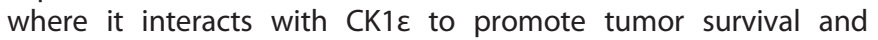
growth after stimulation with Wnt5a to activate phosphoinositide 3-kinase (PI3K)/AKT signaling. ${ }^{56}$

\section{DEAD-box helicases}

DEAD-box helicases (DDXs), named for a conserved amino-acid sequence in their ATP-binding domain (Asp-Glu-Ala-Asp), belong to a highly conserved family of ATP-dependent DNA/RNA helicases. ${ }^{57}$ They consist of a highly conserved helicase core with two domains, displaying high similarity to the recA bacterial DNA recombination protein (Figure 3$).{ }^{58}$ These multifunctional proteins have roles in translation initiation, pre- and posttranslational modifications, DNA repair, microRNA (miR) processing, ribosome biogenesis and RNA decay. ${ }^{59-61}$ Furthermore, DDXs have been recently implicated in breast tumorigenesis and activation of cancer stem cell (CSC) stemness through various pathways, including Wnt. ${ }^{62,63}$ DDXs can be regulated by $\beta$-catenin/TCF-driven transcription and have also been shown to regulate upstream Wnt signaling. The role of DDXs is discussed in further detail later in the section titled 'DDXs, Wnt and TNBC'.

\section{BREAST CANCER SUBTYPES}

Breast cancer is a diverse and complex disease, broadly characterized by four molecularly distinct subtypes, including luminal A, luminal B, HER2-overexpressed and triple-negative breast cancer (TNBC). ${ }^{64}$ The luminal A subtype is characterized as ER/PR-positive and HER2-negative, expressing Bcl-2, cytokeratin $8 / 18$ and low Ki67. ${ }^{65}$ Luminal B subtypes are more aggressive $\mathrm{ER}^{+}$ breast tumors, characterized as HER2 ${ }^{-}$with high Ki67, or HER2 ${ }^{+}$, $\mathrm{PR}^{-}$and $\mathrm{ER}^{+}{ }^{66}$ with cyclin B1 overexpression. ${ }^{67}$ The HER2 subtype is characterized by amplification of the ERBB2/HER2 gene. ${ }^{68}$

TNBC, including basal-like and claudin-low subtypes, accounts for $10-20 \%$ of breast cancers and is characterized by a lack of PR, ER and HER2 overexpression. ${ }^{69}$ TNBC patients present with higher

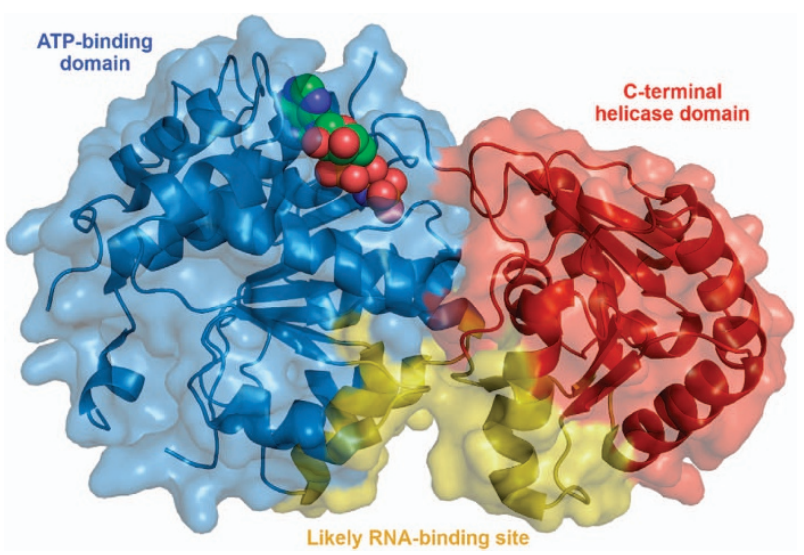

Figure 3. X-ray crystal structure of the ATP-binding and C-terminal helicase domains of the DEAD-box helicase DDX3 (PDB 5E7M). AMP-PNP, a non-hydrolyzable ATP analog, is shown in spheres in the ATP-binding site. 
Table 1. Summary of the six molecular subtypes of TNBC characterized by Lehmann et al. ${ }^{73}$

\begin{tabular}{|c|c|c|}
\hline TNBC subtype & Gene ontology pathway (GOP) & Genes found in GOPs with Wht association \\
\hline Luminal androgen receptor (LAR) & $\begin{array}{l}\text { Steroid pathway } \\
\text { Androgen metabolism } \\
\text { Fatty-acid synthesis }\end{array}$ & $\begin{array}{l}F K B P 5^{74} \\
S P D E F^{75} \\
\text { FASN }^{76}\end{array}$ \\
\hline $\begin{array}{l}\text { Mesenchymal (M)/mesenchymal stem-like } \\
\text { (MSL) }\end{array}$ & EMT & MMP2, ${ }^{77}$ SNAI2, ${ }^{77}$ TCF $4{ }^{77}$ TWIST1, $^{77}$ ZEB $^{78}$ \\
\hline $\begin{array}{l}\text { Basal } 1 \text { (BL1)/Basal } 2 \text { (BL2) } \\
\text { Immunomodulatory (IM) }\end{array}$ & $\begin{array}{l}\text { Wnt/ } \beta \text {-catenin signaling } \\
\text { DNA damage } \\
\text { Proliferation/cell cycle } \\
\text { JAK/STAT cytokine pathway } \\
\text { IL7 pathway }\end{array}$ & 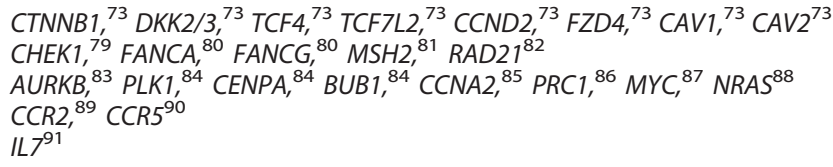 \\
\hline
\end{tabular}

Abbreviations: EMT, epithelial-mesenchymal transition; IL, interleukin; TNBC, triple-negative breast cancer. Various gene ontology pathways were found to be enriched in the LAR, MSL, BL1, BL2 and IM subtypes. Analysis of the genes enriched in these pathways identified genes associated with Wnt signaling.

incidence of distant disease recurrence within 3 years of diagnosis, with a high frequency of visceral metastases. ${ }^{70}$ The prognosis for patients diagnosed with TNBC is poor, with patients who respond poorly to adjuvant treatment exhibiting worse outcomes. ${ }^{4}$

\section{TNBC subtypes}

TNBC has been categorized into a number of distinct molecular subtypes; however, there remains much intertumoral mutational and transcriptional heterogeneity within these subtypes. The molecular heterogeneity of TNBC confounds the clinical approach to TNBC treatment. TNBCs are characterized by high clonal frequencies of single gene mutations in the key tumorigenesis driver genes, including TP53, PIK3CA and PTEN, indicating that clonal evolution of these mutated genes is an early event in TNBC development. $^{71}$ However, mutation frequencies within these genes are not uniform among TNBC cases. ${ }^{71,72}$

Lehmann et al. $^{73}$ determined gene expression signatures in 587 TNBC cases from 21 breast cancer data sets and identified six molecularly distinct TNBC subtypes. These include basal-like 1, basal-like 2, immunomodulatory, mesenchymal (M), mesenchymal stem-like (MSL), and luminal androgen receptor (LAR). These subtypes, various gene ontology pathways and associated Wnt genes are described in Table 1. Recent RNA profiling performed by Burstein et al. ${ }^{92}$ showed overlap of LAR and MES subtypes based on Lehmann's gene expression profiling, but was unable to reproduce all observations. ${ }^{92}$ The findings of both of these studies indicate the presence of at least four molecularly distinct and stable TNBC subtypes, defined as LAR, mesenchymal (MES), basallike immune-suppressed (BLIS) and basal-like immune-activated (BLIA) ${ }^{92}$ Furthermore, these studies suggest molecular targets for the development of therapeutics specific to the treatment of TNBC.

\section{LAR subtype}

The LAR subtype accounts for $\sim 10 \%$ of TNBCs, whereby tumor cells exhibit positive staining for androgen receptors (ARs) and are driven by AR signaling. ${ }^{69,73}$ The LAR subtype of TNBC displays genomic amplification of CCND1, a gene regulated by the Wnt/ $\beta$-catenin pathway. ${ }^{92}$ There is some discordance within the literature in regards to the prognostic utility of AR status, with studies indicating no significant effect on survival rates associated with AR expression, ${ }^{93}$ although $\mathrm{AR}^{+}$TNBC individuals have been shown to have a positive clinical response to the nonsteroidal antiandrogen, bilcautamide. ${ }^{94,95}$ In a study designed to test the benefit of tamoxifen on $\mathrm{ER}^{-}$and TNBC patients, it was found that expression of $\mathrm{AR}^{+}$versus $\mathrm{AR}^{-}$individuals predicted a decreased recurrence rate and treatment benefit with $\mathrm{AR}^{+}$patients; ${ }^{96}$ this is a result of tamoxifen exhibiting agonist activity on AR-expressing cells. ${ }^{97}$
MES subtype

The MES subtype, encompassing Lehmann's M, MSL and claudin-low subtypes, is characterized by the overexpression of genes associated with cellular motility, proliferation and growth signaling pathways. ${ }^{73,92}$ MES subtypes have high expression of platelet-derived growth factor, insulin-like growth factor 1 and c-kit. ${ }^{92}$ MES tumors express mesenchymal stem cell markers, including the breast stem cell marker ALDH1A1, and are enriched in genes associated with epithelial-mesenchymal transition (EMT) and other stem-like properties. ${ }^{73,98}$ Within Lehmann's M and MSL subtypes, there are a number of enriched genes associated with EMT that are also modulated by Wnt signaling, including MMP2, TWIST, SNAI2 and TCF4. ${ }^{77}$ A gene set involved in Wnt/ $\beta$-catenin signaling in the $\mathrm{M}$ and MSL subtypes, including CTNNB1 ( $\beta$-catenin), DKK2, DKK3, SFRP4, TCF4, TCF7L2 and FZD4, was also found to be enriched. ${ }^{73}$ MES tumors are associated with a poorer distant metastasis-free survival at 5 years compared to other subtypes, likely associated with increased expression of cellular motility genes leading to increased metastasis. ${ }^{73}$

\section{BLIS subtype}

BLIS is characterized as an immune-suppressed TNBC subtype with downregulated immune signaling pathways and reduced expression of immune function genes. ${ }^{92,99}$ BLIS tumors exhibit enhanced expression of mitotic and cell cycle pathway genes, with overexpression of proliferative genes, including CENPF, BUB1 and $P R C 1,{ }^{99}$ Sry-related HMG box (SOX) transcription factors, and the immune-regulatory molecule $\mathrm{V}$-domain-containing T-cell activation inhibitor. ${ }^{92}$ SOX transcription factors share a closely related consensus binding sequence to TCF/LEF transcription factors $^{100}$ and are known modulators of $\mathrm{Wnt} / \beta$-catenin signaling. ${ }^{101}$ Survival analysis shows that patients with the BLIS subtype TNBC experience lower rates of recurrence-free survival compared to other TNBC subtypes. ${ }^{99}$

\section{BLIA subtype}

The BLIA subtype is characterized by upregulation of immune activating pathways, with overexpression of STAT transcription factors and cytotoxic T-lymphocyte-associated protein $4 .{ }^{92}$ Furthermore, the BLIA subtype demonstrates amplification of $C D K 1$, which was recently found to phosphorylate the Wnt regulator TAZ. ${ }^{92,102}$ BLIA tumors have increased levels of lymphocytic infiltration and are thus associated with improved disease-free survival rates and patient outcomes compared to other TNBC subtypes, although still associated with a relatively high risk of recurrence $(\sim 20 \%))^{92,103}$ 
Wnt dysregulation in TNBC and TNBC stem cells

Aberrant Wnt signaling is a characteristic of TNBC, with both canonical and non-canonical pathways implicated in TNBC tumorigenesis ${ }^{104,105}$ and metastasis. ${ }^{106}$ Enrichment of Wnt/ $\beta$-catenin signaling is evident in TNBC and is associated with poor clinical outcomes within this subtype. ${ }^{107,108}$ TNBC patients displaying dysregulated $\mathrm{Wnt} / \beta$-catenin signaling are more likely to develop lung and brain secondary metastases. ${ }^{106}$ Studies have shown that nuclear accumulation of $\beta$-catenin promotes cell migration, colony formation, stem-like features and chemoresistance of TNBC cells in vitro and TNBC tumorigenesis in mouse cancer models, thus suggesting that canonical Wnt signaling is a major driving force of TNBC tumorigenesis. ${ }^{104}$ Although the Wnt/B-catenin pathway is associated with the clinicopathological features of TNBC, this is not due to CTNBB1 mutations. ${ }^{108}$ Studies have also implicated dysregulation of non-canonical Wnt signaling pathways in the highly metastatic behavior of TNBC cells and CSCs, specifically through aberrant c-Jun $\mathrm{N}$-terminal kinase activation. $^{109}$

CSCs, or cancer stem-like cells, are a small subset of cells within the heterogeneous tumor bulk that are thought to be responsible for tumor initiation. ${ }^{110}$ These cells also have intrinsic mechanisms for chemoresistance, such as upregulation of drug transporters, including the breast cancer resistance protein (also known as $\left.A B C G^{2}\right){ }^{111}$ By evading the standard chemotherapeutic treatments, it is thought that the CSCs are also responsible for the relapse experienced in many cancers, especially TNBCs. ${ }^{112}$ Studies have also shown that these cells are a main contributor to metastasis, and are able to initiate solid tumor formation when xenotransplanted at low cell densities. ${ }^{113}$ TNBC stem cells are isolated from tumors as $\mathrm{CD}_{4} 4^{+}$(homing cell adhesion molecule), $\mathrm{CD} 24^{-}$(heat stable antigen), $\mathrm{CD}_{49 f^{+}}$cells. ${ }^{114} \mathrm{CSC}$ also differ metabolically to other cancer cells. They are more reliant on mitochondrial respiration, which is supported by their higher mitochondrial reactive oxygen species, enhanced oxygen consumption and higher mitochondrial mass, allowing for features such as resistance to DNA damage. ${ }^{115}$

Wnt signaling is essential for normal breast stem cell function and mammary gland development during embryogenesis, postnatal development and pregnancy, ${ }^{116}$ with adult mammary glands containing Wnt-responsive stem cell populations. ${ }^{117}$ Studies have shown that aberrant Wnt signaling in breast cancer stem cells (BCSCs) is a key event in breast tumorigenesis. ${ }^{118}$ Wnt/ $\beta$-catenin signaling has been linked to TNBC tumorigenesis by regulating the key tumor-associated characteristics, including migration, stemness, proliferation and chemoresistance in TNBC cells and CSCs. ${ }^{104} \mathrm{~A}$ recent study has also demonstrated that Wnt/ $\beta$-catenin signaling activity is higher in breast CSCs than the bulk tumor population, based on $\beta$-catenin, TCF4 and LEF1 expression in Aldefluor-positive cells versus Aldefluor-negative cells. ${ }^{119}$ Treatment with Wnt3a increased the number of $\mathrm{ALDH}^{+}$ breast CSCs, and knockdown of Wnt1 reduced the tumor-forming efficiency of breast CSCs in vitro. ${ }^{119}$

Furthermore, studies have shown that Wnt-derived breast tumors are maintained by clones capable of re-activating Wnt overexpression post-Wnt inhibition, indicating that aberrant Wnt activation is a key driver of breast cancer recurrence and progression. ${ }^{120} \mathrm{~A}$ recent review highlighted the potential importance of $W n t / \beta$-catenin signaling, along with other developmental signaling pathways, including Cripto- 1 and Notch/CSL, in the regulation of TNBC stem cells and therapy resistance in TNBC. ${ }^{121}$ An overview of Wnt signaling dysregulation is given in Figure 4.

\section{FZDs in TNBC}

FZD6. FZD6 exhibits increased gene copy number variations and overexpression in breast cancers. This is more frequent in TNBC than $\mathrm{ER}^{+}$tumors. A study by Corda et al. ${ }^{122}$ determined that FZD6

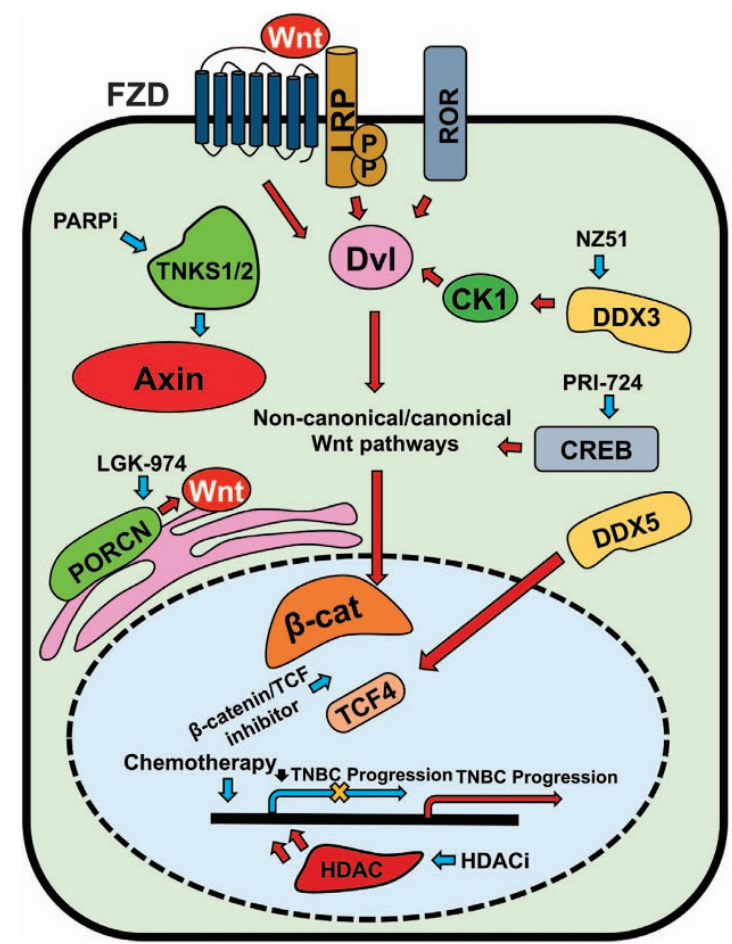

Figure 4. Overview of Wnt signaling regulators contributing to TNBC progression and their targeted therapies. Canonical and non-canonical Wnt pathways are activated through Fzd, LRP and ROR receptors. Blue arrows indicate suppression/inhibition of Wnt regulators and pathways (with a net result of downregulation of Wnt target gene transcription, indicated by yellow cross); red arrows indicate activation of Wnt regulators and pathways.

was involved in the regulation of cell motility, invasion and threedimensional (3D) growth, although it did not regulate proliferation in TNBC. This was confirmed by a significant reduction in distant metastases detected in various organs in vivo after the injection of MDA-MB-231 cells depleted of FZD6. Short hairpin RNA directed at FZD6 in vitro was found to reduce cell invasion through a reduction in active $\mathrm{Rho}$ and the subsequent reduction in fibronectin fibres. This indicated that FZD6 regulates cell motility and invasion through non-canonical Wnt signaling. This study also suggests that FZD6 overexpression in TNBC has a high prognostic value in determining the risk of metastasis. ${ }^{122}$

FZD7. Microarray analysis determined that FZD7 expression is upregulated in TNBC tissue and cell lines, and promotes tumorigenesis via canonical Wnt signaling pathways. ${ }^{123}$ Short hairpin RNA-mediated silencing of FZD7 reduced invasiveness and colony formation in TNBC cell lines. ${ }^{123}$ A recent study found that $\triangle N$ p63, an isoform of Transformation-related protein 63 (p63), enhanced FZD7 expression and increased Wnt signaling in TNBC tumor tissue and cell lines. ${ }^{124}$

Aberrant FZD7 expression is implicated in TNBC stem cell-mediated tumorigenesis. A study recently found that knockdown of $\triangle N$ p63 in TNBC cell lines decreased FZD7 expression and tumorsphere formation, indicating that $\triangle N p 63 / F Z D 7$ upregulation induced TNBC stem cells and promoted tumor formation in TNBC. ${ }^{124}$ The findings of this study highlight the potential clinical importance of $\triangle N p 63 / F Z D 7-W n t$ signaling in TNBC stem cells as a key driver of tumorigenesis and progression of TNBC. ${ }^{124,125}$

FZD8. Gene expression studies have recently linked FZD8-driven Wnt signaling to chemoresistance in TNBC cell lines and TNBC stem cells. Treatment with cisplatin and tumor necrosis factorrelated apoptosis-inducing ligand (TRAIL) in TNBC cell lines 
resulted in increased FZD8 expression in residual tumors of xenograft models. ${ }^{126}$ Furthermore, FZD8 silencing led to increased Wnt pathway-driven TNBC cell apoptosis in vitro and in vivo. ${ }^{126}$ The study showed that treatment with TRAIL/cisplatin increased expression of LEF-1 and TCF-7 in residual TNBC stem cells, thus implicating upregulation of Wnt signaling components in the development of chemoresistance. ${ }^{126}$ An inverse correlation between FZD8 and miR-100 was shown, where decreased miR-100 expression was linked to increased FZD8 expression and Wnt signaling, resulting in increased loco-regional breast cancer metastasis. ${ }^{126,127}$ The role of miRs in Wnt signaling and TNBC is discussed in further detail below. c-Myc overexpression has been linked to FZD8 overexpression in TNBC cell lines, associating c-Myc-driven transcription to chemoresistance and TNBC CSC survival. ${ }^{128}$

\section{LRP5/6 in TNBC}

LRP5/6 are essential for normal mammary development by regulating breast stem cell activity and are linked to basalderived breast tumorigenesis. ${ }^{129-131}$ Studies in transgenic mice indicated that LRP5 knockdown led to resistance to Wnt1-induced tumor formation. ${ }^{130}$

Gene expression analyses found that LRP6 is overexpressed in human TNBC. ${ }^{123,131}$ In vivo studies have shown that LRP6 silencing inhibited tumor growth in TNBC cell line-derived xenograft models. $^{132}$ LRP6 and Wnt target gene SOX9 have been shown to influence regulation of one another in TNBC cell lines. LRP6 overexpression led to SOX9 upregulation, while knockdown of SOX9 reduced LRP6 transcription and decreased cell invasion and proliferation. ${ }^{133}$

LRP6 overexpression led to the upregulation of Wnt signaling and was associated with increased stemness in TNBC cells. ${ }^{134}$ CD138 (Syndecan-1) is an EMT marker associated with both development and breast tumorigenesis, ${ }^{135}$ and has been shown to modulate TNBC stem cell properties by targeting Wnt signaling. ${ }^{134}$ Ibrahim et al. ${ }^{134}$ showed that CD138 modulates Wnt signaling in TNBC stem cells through LRP6, whereby CD138 silencing resulted in downregulated LRP6 expression and Wnt signaling. ${ }^{134}$

\section{RORs in TNBC}

Primary breast cancer DNA microarray data set analysis has shown that ROR1 is expressed on breast cancer cells and absent in normal breast cells, with high ROR1 expression associated with poorer survival. ${ }^{136}$ Furthermore, the study showed that ROR1 silencing in TNBC cell lines increased apoptosis and reduced cell growth. High ROR1 expression in breast cancer cells is associated with high expression of EMT gene profiles and high incidences of disease recurrence and progression. ${ }^{137}$ ROR1 knockdown in TNBC cell lines resulted in reduced EMT-associated protein expression, reduced cell migration and invasion in vitro, and inhibited metastasis in xenograft models. ${ }^{137}$ ROR2 expression is present in both TNBC and non-TNBC, with ROR2 ${ }^{+}$TNBC patients exhibiting poorer survival outcomes compared to other subtypes. ${ }^{138}$ ROR2 knockdown in TNBC cell lines inhibited Wnt signaling and reduced TCF/LEF transcription. ${ }^{138}$ These findings indicate the potential prognostic and therapeutic significance of high ROR1/2 expression in TNBC.

\section{DDXs, WNT and TNBC}

$D D X 3$. DDX3 is a regulator of $\mathrm{Wnt} / \beta$-catenin signaling, where it interacts with and increases the kinase activity of casein kinase $1 \varepsilon$ and is required for the phosphorylation of Dvl2. ${ }^{139}$ It is known to have an oncogenic role in breast cancer, where non-tumorigenic MCF10A cell lines overexpressing DDX3 showed increased EMT, motility and invasiveness. ${ }^{140}$ The same study demonstrated that DDX3 expression was positively correlated with a more aggressive phenotype, and was highly expressed in TNBC cell lines. DDX3 overexpression resulted in E-cadherin downregulation and subsequent nuclear $\beta$-catenin translocation. ${ }^{140}$ Similarly, DDX3 inhibition by NZ51, a ring-expanded nucleoside analog that is predicted to bind to the ATP-binding site of DDX3, led to decreased proliferation, motility and invasiveness in TNBC cell lines and reduced tumor load and metastatic burden in preclinical in vivo models. ${ }^{141}$

DDX5 (p68). DDX5 acts as a co-activator of Wnt/ $\beta$-catenin signaling through regulation of TCF4 expression. In turn, $\beta$-catenin/TCF4 regulates DDX5 expression, forming a positive feedback loop associated with increased EMT marker expression in TNBC cells. ${ }^{142}$ DDX5 is thought to regulate p53-mediated repair of DNA damage, and DDX5 overexpression contributes to tumorigenesis and progression in breast cancers. ${ }^{143}$ DDX5 is highly expressed in basal-like breast cancers compared to luminal-like, and correlates with high EGFR and Ki67 expression in TNBC tissue. ${ }^{144}$ Furthermore, the study found that DDX5 regulates the expression of miR-21 and miR-182 in basal breast cancers, and is associated with malignant disease.

\section{THE ROLES OF MIRS IN WNT SIGNALING AND TNBC}

miRs are endogenous, short, non-coding RNA molecules that regulate cancer-related genes at the post-transcriptional level. ${ }^{145}$ miRs are differentially expressed in BCSCs and cancer cells, indicating that breast cancer-specific miRs are important in maintaining stemness and promoting tumorigenesis in BCSCs. ${ }^{146}$ Twenty-seven miRs differentially expressed in locally advanced TNBC have been previously identified, with many of these predicted to be involved in regulation of Wnt signaling pathway genes. ${ }^{147,148}$

miR-374a overexpression led to suppression of Wnt pathway inhibiting components (PTEN and WIF1) and ultimately increased Wnt-mediated EMT and metastasis in multiple TNBC cell lines. ${ }^{149}$

miR-340 is downregulated in TNBC cell lines and has been linked with TNBC tumorigenesis regulation in multiple studies. ${ }^{150}$ Induction of miR-340 resulted in downregulation of Wnt pathway target genes (CTNNB1, MYC and ROCK1), decreased proliferation and increased apoptosis in a metastatic TNBC cell line. The study showed that miR-340 overexpression reduced cell motility and invasiveness, indicating that miR-340 has a fundamental role in regulating breast metastases. ${ }^{151}$ Another study recently found that induction of miR-340 in TNBC cell lines led to reduced expression of SOX2, an oncogene associated with the canonical Wnt signaling pathway. $^{152}$

A study by Isobe et al. ${ }^{153}$ found that miR-142 upregulation is associated with BCSCs and activates canonical Wnt signaling by promoting APC breakdown in TNBC cell lines. The study found that miR-142 expression activated canonical Wnt signaling, leading to increased miR-150 expression, thereby contributing to breast tissue hyperproliferation, BCSC proliferation and reducing apoptosis in TNBC cell lines. ${ }^{153}$

A recent study has shown that miR-218-5p expression was significantly increased in TNBC, as well as bone metastases, from breast cancer patients. ${ }^{154}$ Anti-miR-218-5p led to a reduction in cell proliferation in vitro and decreased tumor growth, active osteoclasts and osteolytic lesions in vivo, while the opposite was seen with transfection of miR-218-5p. The miR was also shown to directly modulate $\mathrm{Wnt} / \beta$-catenin signaling by binding to secreted FZD-related protein 1 and SOST. Anti-miR-218-5p suppressed Wnt signaling, which downregulated Parathyroid hormone-related protein expression, reducing breast cancer-induced osteolytic disease. $^{154}$ 


\section{CURRENT AND EMERGING THERAPIES FOR TNBC AND TNBC STEM CELLS}

Systemic cytotoxic chemotherapy is clinically indicated in early TNBC and is associated with a greater treatment benefit than hormone receptor-positive tumors. ${ }^{155}$ Numerous early-phase clinical trials are currently underway, investigating various targeted molecules and combination therapies for the treatment of TNBC. In this section, we review current and emerging small molecule therapeutics for the treatment of TNBC (Figure 4); immunotherapeutics are reviewed elsewhere. ${ }^{7}$

\section{Chemotherapy}

Anthracycline/taxane-based regimens are currently the standard of care in the treatment of adjuvant and neoadjuvant TNBC. However, a recent in vitro study has shown that treatment with docetaxel or doxorubicin had transient and negligible impact on cell growth in two TNBC cell lines, respectively. Furthermore, the study found that docetaxel and doxorubicin treatment resulted in deregulation of genes associated with stemness in TNBC cells. ${ }^{156}$ Molecular analysis found that doxorubicin treatment deregulated stem cell signaling pathways associated with cell growth, renewal and differentiation, with altered gene expression demonstrated in components of the Wnt signaling pathway, including FZD2, FZD4, FZD5, FZD6, FZD7, FZD9, Axin1, Wnt11, Wnt10a and Wnt5a. As such, the study concluded that docetaxel and doxorubicin induce stemness in differentiated TNBC cells, which likely accounts for acquired chemoresistance seen in refractory TNBC tumors. ${ }^{156}$

\section{Platinum agents}

Platinum-based chemotherapeutics are a class of DNA-damaging agents, including cisplatin, carboplatin and oxaliplatin; these have established efficacy in breast cancer treatment. ${ }^{157}$ In vitro studies have indicated that combining TRAIL and cisplatin significantly increased BCSC death compared to other standard of care treatments in TNBC cell lines. ${ }^{158}$ The study showed that treatment with TRAIL and cisplatin inhibited Wnt1-mediated signaling and expression of cyclin D1, as well as the phosphorylation of $\beta$-catenin. Combination treatment with cisplatin and TRAIL also enhanced apoptosis, and inhibited proliferation and tumorsphere formation. ${ }^{158}$

\section{Wnt signaling inhibitors}

Treatment with the small molecule $\beta$-catenin/TCF inhibitor CWP232228 inhibited $\beta$-catenin-mediated transcription, leading to inhibition of stem cell proliferation and reduction in tumor bulk in TNBC cell lines and TNBC patient-derived xenograft models, respectively. ${ }^{159}$ PRI-724, a CREB-binding protein inhibitor, and LGK-974, a Porcupine inhibitor, are two small molecules currently undergoing clinical development. Both molecules are currently under investigation for single agent use in ongoing phase I clinical trials in TNBC patients, ${ }^{160}$ with interim results yet to be released. Recent in vitro studies have shown that LGK-974 in combination with the PI3K/AKT/mTOR inhibitor BKM120 worked synergistically to decrease cell viability and enhance antitumor efficacy in TNBC cell lines. ${ }^{161}$

\section{PARP inhibitors}

Poly (ADP-ribose) polymerase (PARP) is an enzyme involved in DNA repair mechanisms necessary for maintaining BRCA-mutated cell viability. ${ }^{162,163}$ Included in the PARP enzyme family are tankyrase (TNKS)-1 and TNKS2. TNKS1 and TNKS2 are regulators of Wnt signaling through their interaction with Axin. ${ }^{164,165}$ TNBCs share phenotypic characteristics with BRCA-mutated cancers, thus providing support for the use of PARP inhibitors. ${ }^{166}$ The small molecule TNKS1/2 inhibitor XAV939 showed effectiveness in the destabilization of Axin and reduction of Wnt activity, although data suggest that a combination approach may be more beneficial. ${ }^{165}$ Clinical trials evaluating the oral PARP inhibitor olaparib in BRCA1/2-positive metastatic breast cancer are currently underway, with interim results showing efficacy. ${ }^{167}$ Veliparib is another PARP inhibitor currently being evaluated in combination with paclitaxel and carboplatin for metastatic TNBC. ${ }^{168}$ Data from Phase I clinical trials of veliparib show acceptable safety, tolerance and good antineoplastic activity. ${ }^{168}$

\section{Histone deacetylase inhibitors}

Histone deacetylase (HDAC) inhibitors are emerging as promising anti-TNBC agents because of their multifunctional capacity to regulate gene expression, cell growth and survival, as well as their ability to restore cellular aberrations due to epigenetic effects. ${ }^{169}$ Entinostat is an HDAC inhibitor recently shown to have anti-CSC effects in TNBC stem cells. An in vivo study found that entinostat treatment reduced TNBC stem cell populations, tumorsphere formation and miR-181a expression in TNBC cell lines. ${ }^{170}$ Furthermore, the study found that entinostat treatment in TNBC patient-derived xenografts reduced tumor growth and inhibited the development of lung metastases. ${ }^{170}$ Further in vivo studies have shown that triple therapy, combining entinostat, all-trans retinoic acid and doxorubicin, induced apoptosis of TNBC stem cells in culture and induced differentiation of TNBC CSCs both in vitro and in vivo. ${ }^{171}$ Panobinostat (LBH589) decreased cell survival and cell cycle progression at the G2/M stage in TNBC cell lines and in vivo. It also increased acetylation of the histones H3 (Lys3) and H4 (Lys8). ${ }^{169}$ Treatment with panobinostat upregulated cadherin-1 (CDH1) and reversed the M phenotype; $\mathrm{CDH} 1$ has been identified as a Wnt-signaling component in invasive breast carcinoma. ${ }^{172}$ An in vivo study found that salinomycin, a compound that selectively inhibits $\mathrm{CSCS}^{173}$ in combination with panobinostat, significantly inhibited the growth of TNBC stem cells in TNBC patient-derived xenografts. The study found that salinomycin and panobinostat worked synergistically to inhibit cell cycle progression, enhance apoptosis and regulate EMT in TNBC stem cells. ${ }^{173}$

\section{CONCLUSIONS}

The dysregulation of Wnt signaling is synonymous with cancer. TNBC is an aggressive, highly proliferative phenotype, which is characteristic of overactive signaling pathways. The accelerated development of sequencing technologies has allowed us to characterize the highly heterogeneous molecular landscape of TNBC with unprecedented detail. These technologies have allowed the discovery of new potential therapeutic targets, as well as to suggest where existing drugs may be of therapeutic value, for instance, in the use of tamoxifen on AR-positive TNBC patients. Like TNBC, Wnt signaling is highly complex and not yet fully characterized. The discovery of novel regulators in TNBC, such as DDXs, adds to the complexity, but also presents exciting new opportunities for the development of potential therapeutic targets. Structural knowledge of Wnt pathway proteins and interactions has expanded in recent years, providing opportunities for rational/structure-based drug design of novel cancer therapeutics.

\section{CONFLICT OF INTEREST}

The authors declare no conflict of interest.

\section{ACKNOWLEDGEMENTS}

SP is supported by funds from the Rotary Club of Belmont, Australian Rotary Health Research Fund and Curtin University School of Biomedical Sciences. MA is a recipient 
of an NHMRC Early Career Fellowship (GNT1054245), a Cancer Council of Western Australia Suzanne Cavanagh Early Career Investigator Grant and a Raine Priming Grant. AD is supported by strategic research funds from the School of Biomedical Sciences (Curtin University), Commercialization Advisory Board of Curtin University, Cancer Council of Western Australia and Actinogen Ltd, Perth, Western Australia.

\section{REFERENCES}

1 Chen S, Parmigiani G. Meta-analysis of BRCA1 and BRCA2 penetrance. J Clin Oncol 2007; 25: 1329-1333.

2 Polakis P. Wnt signaling in cancer. Cold Spring Harb Perspect Biol 2012; 4: a008052.

3 Ovcaricek T, Frkovic SG, Matos E, Mozina B, Borstnar S. Triple negative breast cancer-prognostic factors and survival. Radiol Oncol 2011; 45: 46-52.

4 Foulkes WD, Smith IE, Reis-Filho JS. Triple-negative breast cancer. N Engl J Med 2010; 363: 1938-1948.

5 Hudis CA. Trastuzumab--mechanism of action and use in clinical practice. $N$ Engl J Med 2007; 357: 39-51.

6 Jordan VC. Tamoxifen $(\mathrm{ICl} 46,474)$ as a targeted therapy to treat and prevent breast cancer. Br J Pharmacol 2006; 147: S269-S276.

7 Pusztai L, Karn T, Safonov A, Abu-Khalaf MM, Bianchini G. New strategies in breast cancer: immunotherapy. Clin Cancer Res 2016; 22: 2105-2110.

8 Wu G, Huang H, Garcia Abreu J, He X. Inhibition of GSK3 phosphorylation of beta-catenin via phosphorylated PPPSPXS motifs of Wnt coreceptor LRP6. PLOS ONE 2009; 4: e4926.

9 Liu C, Kato Y, Zhang Z, Do VM, Yankner BA, He X. beta-Trcp couples beta-catenin phosphorylation-degradation and regulates Xenopus axis formation. Proc Natl Acad Sci USA 1999; 96: 6273-6278.

10 MacDonald BT, He X. Frizzled and LRP5/6 receptors for Wnt/beta-catenin signaling. Cold Spring Harb Perspect Biol 2012; 4: a007880.

11 Tamai K, Zeng X, Liu C, Zhang X, Harada Y, Chang Z et al. A mechanism for Wnt coreceptor activation. Mol Cell 2004; 13: 149-156.

12 Clevers H. Wnt/beta-catenin signaling in development and disease. Cell 2006; 127: 469-480.

13 Roose J, Molenaar M, Peterson J, Hurenkamp J, Brantjes $\mathrm{H}$, Moerer $\mathrm{P}$ et al. The Xenopus Wnt effector XTcf-3 interacts with Groucho-related transcriptional repressors. Nature 1998; 395: 608-612.

14 Azzolin L, Panciera T, Soligo S, Enzo E, Bicciato S, Dupont S et al. YAP/TAZ incorporation in the beta-catenin destruction complex orchestrates the Wnt response. Cell 2014; 158: 157-170.

15 Li VS, Ng SS, Boersema PJ, Low TY, Karthaus WR, Gerlach JP et al. Wnt signaling through inhibition of beta-catenin degradation in an intact Axin1 complex. Cell 2012; 149: 1245-1256.

16 Azzolin L, Zanconato F, Bresolin S, Forcato M, Basso G, Bicciato S et al. Role of TAZ as mediator of Wnt signaling. Cell 2012; 151: 1443-1456.

17 Taelman VF, Dobrowolski R, Plouhinec JL, Fuentealba LC, Vorwald PP, Gumper I et al. Wnt signaling requires sequestration of glycogen synthase kinase 3 inside multivesicular endosomes. Cell 2010; 143: 1136-1148.

18 Gomez-Orte E, Saenz-Narciso B, Moreno S, Cabello J. Multiple functions of the noncanonical Wnt pathway. Trends Genet 2013; 29: 545-553.

19 Nishita M, Itsukushima S, Nomachi A, Endo M, Wang Z, Inaba D et al. Ror2/Frizzled complex mediates Wnt5a-induced AP-1 activation by regulating Dishevelled polymerization. Mol Cell Biol 2010; 30: 3610-3619.

20 Habu M, Koyama H, Kishida M, Kamino M, lijima M, Fuchigami T et al. Ryk is essential for Wnt-5a-dependent invasiveness in human glioma. J Biochem 2014; 156: 29-38.

21 Golubkov VS, Chekanov AV, Cieplak P, Aleshin AE, Chernov AV, Zhu W et al. The Wnt/planar cell polarity protein-tyrosine kinase-7 (PTK7) is a highly efficient proteolytic target of membrane type- 1 matrix metalloproteinase: implications in cancer and embryogenesis. J Biol Chem 2010; 285: 35740-35749.

22 Li L, Yuan H, Xie W, Mao J, Caruso AM, McMahon A et al. Dishevelled proteins lead to two signaling pathways. Regulation of LEF-1 and c-Jun N-terminal kinase in mammalian cells. J Biol Chem 1999; 274: 129-134.

23 Habas R, Kato Y, He X. Wnt/Frizzled activation of Rho regulates vertebrate gastrulation and requires a novel Formin homology protein Daam1. Cell 2001; 107: 843-854.

24 Wong HC, Bourdelas A, Krauss A, Lee HJ, Shao Y, Wu D et al. Direct binding of the PDZ domain of Dishevelled to a conserved internal sequence in the C-terminal region of Frizzled. Mol Cell 2003; 12: 1251-1260.

25 De A. Wnt/Ca2+ signaling pathway: a brief overview. Acta Biochim Biophys 2011; 43: 745-756.

26 Dejmek J, Safholm A, Kamp Nielsen C, Andersson T, Leandersson K. Wnt-5a/Ca2 +-induced NFAT activity is counteracted by Wnt-5a/Yes-Cdc42-casein kinase 1alpha signaling in human mammary epithelial cells. Mol Cell Biol 2006; 26: 6024-6036.
27 Ishitani T, Kishida S, Hyodo-Miura J, Ueno N, Yasuda J, Waterman M et al. The TAK1NLK mitogen-activated protein kinase cascade functions in the Wnt-5a/Ca(2+) pathway to antagonize Wnt/beta-catenin signaling. Mol Cell Biol 2003; 23: 131-139.

28 Ishitani T, Ninomiya-Tsuji J, Matsumoto K. Regulation of lymphoid enhancer factor $1 / \mathrm{T}$-cell factor by mitogen-activated protein kinase-related Nemo-like kinase-dependent phosphorylation in Wnt/beta-catenin signaling. Mol Cell Biol 2003; 23: 1379-1389.

29 Cadigan KM, Nusse R. Wnt signaling: a common theme in animal development. Genes Dev 1997; 11: 3286-3305.

30 Gao X, Hannoush RN. Single-cell imaging of Wnt palmitoylation by the acyltransferase porcupine. Nat Chem Biol 2014; 10: 61-68.

31 MacDonald BT, Hien A, Zhang X, Iranloye O, Virshup DM, Waterman ML et al. Disulfide bond requirements for active Wnt ligands. J Biol Chem 2014; 289: 18122-18136.

32 Willert K, Brown JD, Danenberg E, Duncan AW, Weissman IL, Reya T et al. Wnt proteins are lipid-modified and can act as stem cell growth factors. Nature 2003; 423: 448-452.

33 Janda CY, Waghray D, Levin AM, Thomas C, Garcia KC. Structural basis of Wnt recognition by Frizzled. Science 2012; 337: 59-64.

34 Dijksterhuis JP, Petersen J, Schulte G. WNT/Frizzled signalling: receptor-ligand selectivity with focus on FZD-G protein signalling and its physiological relevance: IUPHAR Review 3. Br J Pharmacol 2014; 171: 1195-1209.

35 Takada R, Satomi Y, Kurata T, Ueno N, Norioka S, Kondoh H et al. Monounsaturated fatty acid modification of Wnt protein: its role in Wnt secretion. Dev Cell 2006; 11: 791-801.

36 Wang C, Wu H, Katritch V, Han GW, Huang XP, Liu W et al. Structure of the human smoothened receptor bound to an antitumour agent. Nature 2013; 497: 338-343.

37 Wang C, Wu H, Evron T, Vardy E, Han GW, Huang XP et al. Structural basis for Smoothened receptor modulation and chemoresistance to anticancer drugs. Nat Commun 2014; 5: 4355.

38 Weierstall U, James D, Wang C, White TA, Wang D, Liu W et al. Lipidic cubic phase injector facilitates membrane protein serial femtosecond crystallography. Nat Commun 2014; 5: 3309.

39 Byrne EF, Sircar R, Miller PS, Hedger G, Luchetti G, Nachtergaele S et al. Structural basis of Smoothened regulation by its extracellular domains. Nature 2016; 535 : 517-522.

40 Sussman DJ, Klingensmith J, Salinas P, Adams PS, Nusse R, Perrimon N. Isolation and characterization of a mouse homolog of the Drosophila segment polarity gene dishevelled. Dev Biol 1994; 166: 73-86.

41 Gao C, Chen YG. Dishevelled: the hub of Wnt signaling. Cell Signal 2010; 22: 717-727.

42 Fiedler M, Mendoza-Topaz C, Rutherford TJ, Mieszczanek J, Bienz M. Dishevelled interacts with the DIX domain polymerization interface of Axin to interfere with its function in down-regulating beta-catenin. Proc Natl Acad Sci USA 2011; 108: 1937-1942.

43 Schwarz-Romond T, Fiedler M, Shibata N, Butler PJ, Kikuchi A, Higuchi Y et al. The DIX domain of Dishevelled confers Wnt signaling by dynamic polymerization. Nat Struct Mol Biol 2007; 14: 484-492.

44 Gammons MV, Renko M, Johnson CM, Rutherford TJ, Bienz M. Wnt signalosome assembly by DEP domain swapping of Dishevelled. Mol Cell 2016; 64: 92-104.

45 Tauriello DV, Jordens I, Kirchner K, Slootstra JW, Kruitwagen T, Bouwman BA et al. Wnt/beta-catenin signaling requires interaction of the Dishevelled DEP domain and $C$ terminus with a discontinuous motif in Frizzled. Proc Natl Acad Sci USA 2012; 109: E812-E820.

46 Jiang $\mathrm{X}$, Charlat O, Zamponi R, Yang Y, Cong F. Dishevelled promotes Wnt receptor degradation through recruitment of ZNRF3/RNF43 E3 ubiquitin ligases. Mol Cell 2015; 58: 522-533.

47 Gong Y, Bourhis E, Chiu C, Stawicki S, DeAlmeida VI, Liu BY et al. Wnt isoformspecific interactions with coreceptor specify inhibition or potentiation of signaling by LRP6 antibodies. PLOS ONE 2010; 5: e12682.

48 Cheng Z, Biechele T, Wei Z, Morrone S, Moon RT, Wang L et al. Crystal structures of the extracellular domain of LRP6 and its complex with DKK1. Nat Struct Mol Biol 2011; 18: 1204-1210.

49 Ahn VE, Chu ML, Choi HJ, Tran D, Abo A, Weis WI. Structural basis of Wnt signaling inhibition by Dickkopf binding to LRP5/6. Dev Cell 2011; 21: 862-873.

50 Bourhis E, Wang W, Tam C, Hwang J, Zhang Y, Spittler D et al. Wnt antagonists bind through a short peptide to the first beta-propeller domain of LRP5/6. Structure 2011; 19: 1433-1442.

51 Zeng X, Huang H, Tamai K, Zhang X, Harada Y, Yokota C et al. Initiation of Wnt signaling: control of Wnt coreceptor Lrp6 phosphorylation/activation via frizzled, dishevelled and axin functions. Development 2008; 135: 367-375.

52 Minami Y, Oishi I, Endo M, Nishita M. Ror-family receptor tyrosine kinases in noncanonical Wnt signaling: their implications in developmental morphogenesis and human diseases. Dev Dyn 2010; 239: 1-15. 
53 Stiegler AL, Burden SJ, Hubbard SR. Crystal structure of the frizzled-like cysteinerich domain of the receptor tyrosine kinase MuSK. J Mol Biol 2009; 393: 1-9.

54 Schlessinger J. Cell signaling by receptor tyrosine kinases. Cell 2000; 103: 211-225.

55 Liu Y, Rubin B, Bodine PV, Billiard J. Wnt5a induces homodimerization and activation of Ror2 receptor tyrosine kinase. J Cell Biochem 2008; 105: 497-502.

56 Zhang S, Chen L, Cui B, Chuang HY, Yu J, Wang-Rodriguez J et al. ROR1 is expressed in human breast cancer and associated with enhanced tumorcell growth. PLOS ONE 2012; 7: e31127.

57 Jarmoskaite I, Russell R. DEAD-box proteins as RNA helicases and chaperones. Wiley Interdiscip Rev RNA 2011; 2: 135-152.

58 Samatanga B, Klostermeier D. DEAD-box RNA helicase domains exhibit a continuum between complete functional independence and high thermodynamic coupling in nucleotide and RNA duplex recognition. Nucleic Acids Res 2014; 42: 10644-10654.

59 Rocak S, Linder P. DEAD-box proteins: the driving forces behind RNA metabolism. Nat Rev Mol Cell Biol 2004; 5: 232-241.

$60 \mathrm{Li} \mathrm{L}$, Monckton EA, Godbout R. A role for DEAD box 1 at DNA doublestrand breaks. Mol Cell Biol 2008; 28: 6413-6425.

61 Linder P, Jankowsky E. From unwinding to clamping-the DEAD box RNA helicase family. Nat Rev Mol Cell Biol 2011; 12: 505-516.

62 Fuller-Pace FV. DEAD box RNA helicase functions in cancer. RNA Biol 2013; 10: $121-132$.

63 Shin EM, Hay HS, Lee MH, Goh JN, Tan TZ, Sen YP et al. DEAD-box helicase DP103 defines metastatic potential of human breast cancers. J Clin Invest 2014; 124: 3807-3824.

64 Perou CM, Sørlie T, Eisen MB, van de Rijn M, Jeffrey SS, Rees CA et al. Molecular portraits of human breast tumours. Nature 2000; 406: 747-752.

65 Eroles P, Bosch A, Perez-Fidalgo JA, Lluch A. Molecular biology in breast cancer: intrinsic subtypes and signaling pathways. Cancer Treat Rev 2012; 38: 698-707.

66 Creighton CJ. The molecular profile of luminal B breast cancer. Biologics 2012; 6: 289.

67 Eroles P, Bosch A, Pérez-Fidalgo JA, Lluch A. Molecular biology in breast cancer: intrinsic subtypes and signaling pathways. Cancer Treat Rev 2012; 38: 698-707.

68 Prat A, Carey LA, Adamo B, Vidal M, Tabernero J, Cortés J et al. Molecular features and survival outcomes of the intrinsic subtypes within HER2-positive breast cancer. J Natl Cancer Inst 2014; 106: dju152.

69 Abramson VG, Lehmann BD, Ballinger TJ, Pietenpol JA. Subtyping of triplenegative breast cancer: implications for therapy. Cancer 2015; 121: 8-16.

70 Kast K, Link T, Friedrich K, Petzold A, Niedostatek A, Schoffer O et al. Impact of breast cancer subtypes and patterns of metastasis on outcome. Breast Cancer Res Treat 2015; 150: 621-629.

71 Shah SP, Roth A, Goya R, Oloumi A, Ha G, Zhao Y et al. The clonal and mutational evolution spectrum of primary triple-negative breast cancers. Nature 2012; 486: 395-399.

72 Weisman PS, Ng CK, Brogi E, Eisenberg RE, Won HH, Piscuoglio S et al. Genetic alterations of triple negative breast cancer by targeted next-generation sequencing and correlation with tumor morphology. Mod Pathol 2016; 29: 476-488.

73 Lehmann BD, Bauer JA, Chen X, Sanders ME, Chakravarthy AB, Shyr $Y$ et al. Identification of human triple-negative breast cancer subtypes and preclinical models for selection of targeted therapies. J Clin Invest 2011; 121: 2750-2767.

74 Wang G, Wang J, Sadar MD. Crosstalk between the androgen receptor and betacatenin in castrate-resistant prostate cancer. Cancer Res 2008; 68: 9918-9927.

75 Noah TK, Lo YH, Price A, Chen G, King E, Washington MK et al. SPDEF functions as a colorectal tumor suppressor by inhibiting beta-catenin activity. Gastroenterology 2013; 144: 1012-23 e6.

76 Wang H, Xi Q, Wu G. Fatty acid synthase regulates invasion and metastasis of colorectal cancer via Wnt signaling pathway. Cancer Med 2016; 5: 1599-1606.

77 Laezza C, D'Alessandro A, Paladino S, Maria Malfitano A, Chiara Proto M, Gazzerro $P$ et al. Anandamide inhibits the Wnt/beta-catenin signalling pathway in human breast cancer MDA MB 231 cells. Eur J Cancer 2012; 48: 3112-3122.

78 Kahlert UD, Maciaczyk D, Doostkam S, Orr BA, Simons B, Bogiel T et al. Activation of canonical WNT/beta-catenin signaling enhances in vitro motility of glioblastoma cells by activation of ZEB1 and other activators of epithelial-tomesenchymal transition. Cancer Lett 2012; 325: 42-53.

79 Greenow KR, Clarke AR, Williams GT, Jones R. Wnt-driven intestinal tumourigenesis is suppressed by Chk1 deficiency but enhanced by conditional haploinsufficiency. Oncogene 2014; 33: 4089-4096.

80 Huard CC, Tremblay CS, Magron A, Levesque G, Carreau M. The Fanconi anemia pathway has a dual function in Dickkopf-1 transcriptional repression. Proc Natl Acad Sci USA 2014; 111: 2152-2157.

81 Castiglia D, Bernardini S, Alvino E, Pagani E, De Luca N, Falcinelli S et al. Concomitant activation of Wnt pathway and loss of mismatch repair function in human melanoma. Genes Chromosomes Cancer 2008; 47: 614-624.
82 Xu H, Yan Y, Deb S, Rangasamy D, Germann M, Malaterre J et al. Cohesin Rad21 mediates loss of heterozygosity and is upregulated via Wnt promoting transcriptional dysregulation in gastrointestinal tumors. Cell Rep 2014; 9: 1781-1797.

83 Huang YL, Anvarian Z, Doderlein G, Acebron SP, Niehrs C. Maternal Wnt/STOP signaling promotes cell division during early Xenopus embryogenesis. Proc Natl Acad Sci USA 2015; 112: 5732-5737.

84 Kikuchi K, Niikura Y, Kitagawa K, Kikuchi A. Dishevelled, a Wnt signalling component, is involved in mitotic progression in cooperation with Plk1. EMBO J 2010; 29: 3470-3483.

85 Suzuki A, Pelikan RC, Iwata J. WNT/beta-catenin signaling regulates multiple steps of myogenesis by regulating step-specific targets. Mol Cell Biol 2015; 35: 1763-1776.

86 Chiacchiera F, Rossi A, Jammula S, Piunti A, Scelfo A, Ordonez-Moran P et al. Polycomb complex PRC1 preserves intestinal stem cell identity by sustaining Wnt/beta-catenin transcriptional activity. Cell Stem Cell 2016; 18: 91-103.

87 He TC, Sparks AB, Rago C, Hermeking H, Zawel L, da Costa LT et al. Identification of c-MYC as a target of the APC pathway. Science 1998; 281: 1509-1512.

88 Conrad WH, Swift RD, Biechele TL, Kulikauskas RM, Moon RT, Chien AJ. Regulating the response to targeted MEK inhibition in melanoma: enhancing apoptosis in NRAS- and BRAF-mutant melanoma cells with Wnt/beta-catenin activation. Cell Cycle 2012; 11: 3724-3730.

89 Xu M, Wang S, Qi Y, Chen L, Frank JA, Yang XH et al. Role of MCP-1 in alcoholinduced aggressiveness of colorectal cancer cells. Mol Carcinog 2016; 55: 1002-1011.

90 Yasuhara R, Irie T, Suzuki K, Sawada T, Miwa N, Sasaki A et al. The beta-catenin signaling pathway induces aggressive potential in breast cancer by up-regulating the chemokine CCL5. Exp Cell Res 2015; 338: 22-31.

$91 \mathrm{Yu}$ Q, Xu M, Sen JM. Beta-catenin expression enhances IL-7 receptor signaling in thymocytes during positive selection. J Immunol 2007; 179: 126-131.

92 Burstein MD, Tsimelzon A, Poage GM, Covington KR, Contreras A, Fuqua SA et al. Comprehensive genomic analysis identifies novel subtypes and targets of triplenegative breast cancer. Clin Cancer Res 2015; 21: 1688-1698.

93 Pistelli M, Caramanti M, Biscotti T, Santinelli A, Pagliacci A, De Lisa M et al. Androgen receptor expression in early triple-negative breast cancer: clinical significance and prognostic associations. Cancers 2014; 6: 1351-1362.

94 Arce-Salinas C, Riesco-Martinez MC, Hanna W, Bedard P, Warner E. Complete response of metastatic androgen receptor-positive breast cancer to bicalutamide: case report and review of the literature. J Clin Oncol 2016; 34: e21-e24.

95 Gucalp A, Tolaney S, Isakoff SJ, Ingle JN, Liu MC, Carey LA et al. Phase II trial of bicalutamide in patients with androgen receptor-positive, estrogen receptornegative metastatic breast cancer. Clin Cancer Res 2013; 19: 5505-5512.

96 Hilborn E, Gacic J, Fornander T, Nordenskjold B, Stal O, Jansson A. Androgen receptor expression predicts beneficial tamoxifen response in oestrogen receptor-alpha-negative breast cancer. Br J Cancer 2016; 114: 248-255.

97 Ciupek A, Rechoum Y, Gu G, Gelsomino L, Beyer AR, Brusco L et al. Androgen receptor promotes tamoxifen agonist activity by activation of EGFR in ERalphapositive breast cancer. Breast Cancer Res Treat 2015; 154: 225-237.

98 Prat A, Parker JS, Karginova O, Fan C, Livasy C, Herschkowitz Jl et al. Phenotypic and molecular characterization of the claudin-low intrinsic subtype of breast cancer. Breast Cancer Res 2010; 12: 1.

99 Liu Y-R, Jiang Y-Z, Xu X-E, Yu K-D, Jin X, Hu X et al. Comprehensive transcriptome analysis identifies novel molecular subtypes and subtype-specific RNAs of triplenegative breast cancer. Breast Cancer Res 2016; 18: 1.

100 Lefebvre V, Dumitriu B, Penzo-Mendez A, Han Y, Pallavi B. Control of cell fate and differentiation by Sry-related high-mobility-group box (Sox) transcription factors. Int J Biochem Cell Biol 2007; 39: 2195-2214.

101 Kormish JD, Sinner D, Zorn AM. Interactions between SOX factors and Wnt/betacatenin signaling in development and disease. Dev Dyn 2010; 239: 56-68.

102 Zhang L, Chen X, Stauffer S, Yang S, Chen Y, Dong J. CDK1 phosphorylation of TAZ in mitosis inhibits its oncogenic activity. Oncotarget 2015; 6: 31399-31412.

103 Prat A, Pineda E, Adamo B, Galván P, Fernández A, Gaba L et al. Clinical implications of the intrinsic molecular subtypes of breast cancer. Breast 2015; 24: S26-S35.

$104 \mathrm{Xu}$ J, Prosperi JR, Choudhury N, Olopade Ol, Goss KH. $\beta$-Catenin is required for the tumorigenic behavior of triple-negative breast cancer cells. PLOS ONE 2015; 10: e0117097.

105 Mohammed MK, Shao C, Wang J, Wei Q, Wang X, Collier Z et al. Wnt/ $\beta$-catenin signaling plays an ever-expanding role in stem cell self-renewal, tumorigenesis and cancer chemoresistance. Genes Dis 2016; 3: 11-40.

106 Dey N, Barwick BG, Moreno CS, Ordanic-Kodani M, Chen Z, Oprea-llies G et al. Wnt signaling in triple negative breast cancer is associated with metastasis. $B M C$ Cancer 2013; 13: 1.

107 Khramtsov Al, Khramtsova GF, Tretiakova M, Huo D, Olopade OI, Goss KH. Wnt/ $\beta$-catenin pathway activation is enriched in basal-like breast cancers and predicts poor outcome. Am J Pathol 2010; 176: 2911-2920. 
108 Geyer FC, Lacroix-Triki M, Savage K, Arnedos M, Lambros MB, MacKay A et al. betaCatenin pathway activation in breast cancer is associated with triple-negative phenotype but not with CTNNB1 mutation. Mod Pathol 2011; 24: 209-231.

109 Borg J-P, Belotti E, Daulat A, Lembo F, Bertucci F, Charafe-Jauffret E et al. Deregulation of the non-canonical pathway in triple-negative breast cancer. FASEB J 2013; 27: 610.1-.1.

110 Medema JP. Cancer stem cells: the challenges ahead. Nat Cell Biol 2013; 15: 338-344.

111 Sicchieri RD, da Silveira WA, Mandarano LR, de Oliveira TM, Carrara HH, Muglia VF et al. ABCG2 is a potential marker of tumor-initiating cells in breast cancer. Tumour Biol 2015; 36: 9233-9243.

112 Pogoda K, Niwinska A, Murawska M, Pienkowski T. Analysis of pattern, time and risk factors influencing recurrence in triple-negative breast cancer patients. Med Oncol 2013; 30: 388.

113 Cheng L, Ramesh AV, Flesken-Nikitin A, Choi J, Nikitin AY. Mouse models for cancer stem cell research. Toxicol Pathol 2010; 38: 62-71.

114 Atkinson RL, Yang WT, Rosen DG, Landis MD, Wong H, Lewis MT et al. Cancer stem cell markers are enriched in normal tissue adjacent to triple negative breast cancer and inversely correlated with DNA repair deficiency. Breast Cancer Res 2013; 15: R77.

115 Peiris-Pages M, Martinez-Outschoorn UE, Pestell RG, Sotgia F, Lisanti MP. Cancer stem cell metabolism. Breast Cancer Res 2016; 18: 55.

116 van Amerongen R, Bowman AN, Nusse R. Developmental stage and time dictate the fate of Wnt/ $\beta$-catenin-responsive stem cells in the mammary gland. Cell Stem Cell 2012; 11: 387-400.

117 Zeng YA, Nusse R. Wnt proteins are self-renewal factors for mammary stem cells and promote their long-term expansion in culture. Cell Stem Cell 2010; 6: 568-577.

118 Howard B, Ashworth A. Signalling pathways implicated in early mammary gland morphogenesis and breast cancer. PLoS Genet 2006; 2: e112.

119 Jang GB, Kim JY, Cho SD, Park KS, Jung JY, Lee HY et al. Blockade of Wnt/betacatenin signaling suppresses breast cancer metastasis by inhibiting CSC-like phenotype. Sci Rep 2015; 5: 12465.

120 Cleary AS, Leonard TL, Gestl SA, Gunther EJ. Tumour cell heterogeneity maintained by cooperating subclones in Wnt-driven mammary cancers. Nature 2014; 508: 113-117

121 Rangel MC, Bertolette D, Castro NP, Klauzinska M, Cuttitta F, Salomon DS Developmental signaling pathways regulating mammary stem cells and contributing to the etiology of triple-negative breast cancer. Breast Cancer Res Treat 2016; 156: 211-226.

122 Corda G, Sala G, Lattanzio R, lezzi M, Sallese M, Fragassi G et al. Functional and prognostic significance of the genomic amplification of frizzled 6 (FZD6) in breast cancer. J Pathol 2016; 241: 350-361.

123 Yang L, Wu X, Wang Y, Zhang K, Wu J, Yuan Y et al. FZD7 has a critical role in cell proliferation in triple negative breast cancer. Oncogene 2011; 30: 4437-4446.

124 Chakrabarti R, Wei Y, Hwang J, Hang X, Blanco MA, Choudhury A et al. $\Delta N p 63$ promotes stem cell activity in mammary gland development and basal-like breast cancer by enhancing Fzd7 expression and Wnt signalling. Nat Cell Biol 2014; 16: 1004-1015.

125 Phesse T, Flanagan D, Vincan E. Frizzled7: a promising Achilles' heel for targeting the Wnt receptor complex to treat cancer. Cancers 2016; 8: 50.

126 Yin S, Xu L, Bonfil RD, Banerjee S, Sarkar FH, Sethi S et al. Tumor-initiating cells and FZD8 play a major role in drug resistance in triple-negative breast cancer. Mol Cancer Ther 2013; 12: 491-498.

127 Jiang Q, He M, Guan S, Ma M, Wu H, Yu Z et al. MicroRNA-100 suppresses the migration and invasion of breast cancer cells by targeting FZD-8 and inhibiting Wnt/B-catenin signaling pathway. Tumor Biol 2016; 37: 5001-5011.

128 Yin S, Cheriyan VT, Rishi AK, Reddy KB. c-Myc and Frizzled 8 play a major role in the regulation of cancer stem cells and drug resistance in triple-negative breast cancer. Cancer Res 2015; 75: 2225.

129 Badders NM, Goel S, Clark RJ, Klos KS, Kim S, Bafico A et al. The Wnt receptor, Lrp5, is expressed by mouse mammary stem cells and is required to maintain the basal lineage. PLOS ONE 2009; 4: e6594.

130 Lindvall C, Evans NC, Zylstra CR, Li Y, Alexander CM, Williams BO. The Wnt signaling receptor Lrp5 is required for mammary ductal stem cell activity and Wnt1-induced tumorigenesis. Journal of Biological Chemistry 2006; 281: 35081-35087.

131 Lindvall C, Zylstra CR, Evans N, West RA, Dykema K, Furge KA et al. The Wnt co-receptor Lrp6 is required for normal mouse mammary gland development. PLOS ONE 2009; 4: e5813.

132 Liu C-C, Prior J, Piwnica-Worms D, Bu G. LRP6 overexpression defines a class of breast cancer subtype and is a target for therapy. Proc Natl Acad Sci 2010; 107: 5136-5141.

133 Wang H, He L, Ma F, Regan MM, Balk SP, Richardson AL et al. SOX9 regulates low density lipoprotein receptor-related protein 6 (LRP6) and T-cell factor 4 (TCF4) expression and Wnt/ $\beta$-catenin activation in breast cancer. J Biol Chem 2013; 288: 6478-6487.
134 Ibrahim SA, Hassan H, Vilardo L, Kumar SK, Kumar AV, Kelsch R et al. Syndecan-1 (CD138) modulates triple-negative breast cancer stem cell properties via regulation of LRP-6 and IL-6-mediated STAT3 signaling. PLOS ONE 2013; 8: e85737.

135 Nikolova V, Koo C-Y, Ibrahim SA, Wang Z, Spillmann D, Dreier R et al. Differential roles for membrane-bound and soluble syndecan-1 (CD138) in breast cancer progression. Carcinogenesis 2009; 30: 397-407.

136 Zhang S, Chen L, Cui B, Chuang H-Y, Yu J, Wang-Rodriguez J et al. ROR1 is expressed in human breast cancer and associated with enhanced tumorcell growth. PLoS ONE 2012; 7: e31127.

137 Cui B, Zhang S, Chen L, Yu J, Widhopf GF, Fecteau J-F et al. Targeting ROR1 inhibits epithelial-mesenchymal transition and metastasis. Cancer Res 2013; 73: 3649-3660.

138 Henry C, Quadir A, Hawkins N, Jary E, Llamosas E, Kumar D et al. Expression of the novel Wnt receptor ROR2 is increased in breast cancer and may regulate both $\beta$-catenin dependent and independent Wnt signalling. J Cancer Res Clin Oncol 2015; 141: 243-254.

139 Cruciat C-M, Dolde C, de Groot RE, Ohkawara B, Reinhard C, Korswagen HC et al. RNA helicase DDX3 is a regulatory subunit of casein kinase 1 in Wnt- $\beta$-catenin signaling. Science 2013; 339: 1436-1441.

140 Botlagunta M, Vesuna F, Mironchik Y, Raman A, Lisok A, Winnard P et al. Oncogenic role of DDX3 in breast cancer biogenesis. Oncogene 2008; 27: 3912-3922.

141 Xie M, Vesuna F, Botlagunta M, Bol GM, Irving A, Bergman Y et al. NZ51, a ringexpanded nucleoside analog, inhibits motility and viability of breast cancer cells by targeting the RNA helicase DDX3. Oncotarget 2015; 6: 29901-29913.

142 Guturi KKN, Sarkar M, Bhowmik A, Das N, Ghosh MK. DEAD-box protein p68 is regulated by $\beta$-catenin/transcription factor 4 to maintain a positive feedback loop in control of breast cancer progression. Breast Cancer Res 2014; 16: 1.

143 Moore HC, Jordan LB, Bray SE, Baker L, Quinlan PR, Purdie CA et al. The RNA helicase p68 modulates expression and function of the $\Delta 133$ isoform (s) of p53, and is inversely associated with $\Delta 133 \mathrm{p} 53$ expression in breast cancer. Oncogene 2010; 29: 6475-6484.

144 Wang D, Huang J, Hu Z. RNA helicase DDX5 regulates microRNA expression and contributes to cytoskeletal reorganization in basal breast cancer cells. Mol Cell Proteomics 2012; 11: M111. 011932.

145 Esquela-Kerscher A, Slack FJ. Oncomirs-microRNAs with a role in cancer. Nat Rev Cancer 2006; 6: 259-269.

146 Shimono Y, Zabala M, Cho RW, Lobo N, Dalerba P, Qian D et al. Downregulation of miRNA-200c links breast cancer stem cells with normal stem cells. Cell 2009; 138: 592-603.

147 Avery-Kiejda KA, Braye SG, Mathe A, Forbes JF, Scott RJ. Decreased expression of key tumour suppressor microRNAs is associated with lymph node metastases in triple negative breast cancer. BMC Cancer 2014; 14: 1.

148 Goh JN, Loo SY, Datta A, Siveen KS, Yap WN, Cai W et al. microRNAs in breast cancer: regulatory roles governing the hallmarks of cancer. Biol Rev Camb Philos Soc 2016; 91: 409-428.

149 Cai J, Guan H, Fang L, Yang Y, Zhu X, Yuan J et al. MicroRNA-374a activates Wnt/ $\beta$-catenin signaling to promote breast cancer metastasis. J Clin Invest 2013; 123: $566-579$.

150 Wu ZS, Wu Q, Wang CQ, Wang XN, Huang J, Zhao JJ et al. miR-340 inhibition of breast cancer cell migration and invasion through targeting of oncoprotein c-Met. Cancer 2011; 117: 2842-2852.

151 Mohammadi-Yeganeh S, Paryan M, Arefian E, Vasei M, Ghanbarian H, Mahdian R et al. MicroRNA-340 inhibits the migration, invasion, and metastasis of breast cancer cells by targeting Wnt pathway. Tumor Biol 2016; 37: 8993-9000.

152 Mohammadi Yeganeh S, Vasei M, Tavakoli R, Kia V, Paryan M. The effect of miR-340 over-expression on cell-cycle-related genes in triple-negative breast cancer cells. Eur J Cancer Care 2016; 7: 79032-79046.

153 Isobe T, Hisamori S, Hogan DJ, Zabala M, Hendrickson DG, Dalerba $\mathrm{P}$ et al. miR-142 regulates the tumorigenicity of human breast cancer stem cells through the canonical WNT signaling pathway. Elife 2014; 3: e01977.

154 Taipaleenmaki $\mathrm{H}$, Farina $\mathrm{NH}$, van Wijnen AJ, Stein JL, Hesse E, Stein GS et al. Antagonizing miR-218-5p attenuates Wnt signaling and reduces metastatic bone disease of triple negative breast cancer cells. Oncotarget 2016; 7 : 79032-79046.

155 Group EBCTC., Adjuvant chemotherapy in oestrogen-receptor-poor breast cancer: patient-level meta-analysis of randomised trials. Lancet 2008; 371: 29-40.

156 Tudoran O, Soritau O, Balacescu L, Visan S, Barbos O, Cojocneanu-Petric R et al. Regulation of stem cells-related signaling pathways in response to doxorubicin treatment in Hs578T triple-negative breast cancer cells. Mol Cell Biochem 2015; 409: 163-176.

157 Sparano JA. Defining a role and predicting benefit from platinum-based therapy in breast cancer: an evolving story. J Clin Oncol 2015; 33: 1-3.

158 Yin S, Xu L, Bandyopadhyay S, Sethi S, Reddy KB. Cisplatin and TRAIL enhance breast cancer stem cell death. Int J Oncol 2011; 39: 891 
159 Jang G-B, Hong I-S, Kim R-J, Lee S-Y, Park S-J, Lee E-S et al. Wnt/ $\beta$-catenin smallmolecule inhibitor CWP232228 preferentially inhibits the growth of breast cancer stem-like cells. Cancer Res 2015; 75: 1691-1702.

160 Takebe N, Miele L, Harris PJ, Jeong W, Bando H, Kahn M et al. Targeting Notch, Hedgehog, and Wnt pathways in cancer stem cells: clinical update. Nat Rev Clin Oncol 2015; 12: 445-464.

161 Solzak JP, Atale R, Hancock B, Radovich M. Dual PI3K and Wnt pathway inhibition is a synergistic combination against triple-negative breast cancer. Cancer Res 2015; 75: 5340

162 Farmer H, McCabe N, Lord CJ, Tutt AN, Johnson DA, Richardson TB et al. Targeting the DNA repair defect in BRCA mutant cells as a therapeutic strategy. Nature 2005; 434: 917-921.

163 Bryant HE, Schultz N, Thomas HD, Parker KM, Flower D, Lopez E et al. Specific killing of BRCA2-deficient tumours with inhibitors of poly (ADP-ribose) polymerase. Nature 2005; 434: 913-917.

164 Huang SM, Mishina YM, Liu S, Cheung A, Stegmeier F, Michaud GA et al. Tankyrase inhibition stabilizes axin and antagonizes Wnt signalling. Nature 2009; 461: 614-620.

165 Bao R, Christova T, Song S, Angers S, Yan X, Attisano L. Inhibition of tankyrases induces Axin stabilization and blocks Wnt signalling in breast cancer cells. PLOS ONE 2012; 7: e48670.

166 Livraghi L, Garber JE. PARP inhibitors in the management of breast cancer: current data and future prospects. BMC Med 2015; 13: 1.

167 Kaufman B, Shapira-Frommer R, Schmutzler RK, Audeh MW, Friedlander M, Balmaña J et al. Olaparib monotherapy in patients with advanced cancer and a germline BRCA1/2 mutation. J Clin Oncol 2015; 33: 244-250.

168 Pahuja S, Beumer JH, Appleman LJ, HA-H Tawbi, Stoller RG, Lee JJ et al. (eds). in ASCO Annual Meeting Proceedings, Chicago, IL, USA; 29 May-2 June, 2015.
169 Tate CR, Rhodes LV, Segar HC, Driver JL, Pounder FN, Burow ME et al. Targeting triple-negative breast cancer cells with the histone deacetylase inhibitor panobinostat. Breast Cancer Res 2012; 14: R79.

170 Schech A, Kazi A, Yu S, Shah P, Sabnis G. Histone deacetylase inhibitor entinostat inhibits tumor-initiating cells in triple-negative breast cancer cells. Mol Cancer Ther 2015; 14: 1848-1857.

171 Merino VF, Nguyen N, Jin K, Sadik H, Cho S, Korangath P et al. Combined treatment with epigenetic, differentiating, and chemotherapeutic agents cooperatively targets tumor-initiating cells in triple-negative breast cancer. Cancer Res 2016; 76: 2013-2024.

172 Prasad CP, Mirza S, Sharma G, Prashad R, DattaGupta S, Rath G et al. Epigenetic alterations of $\mathrm{CDH} 1$ and $\mathrm{APC}$ genes: relationship with activation of Wnt/betacatenin pathway in invasive ductal carcinoma of breast. Life Sci 2008; 83: 318-325.

173 Kai M, Kanaya N, Wu SV, Mendez C, Nguyen D, Luu T et al. Targeting breast cancer stem cells in triple-negative breast cancer using a combination of LBH589 and salinomycin. Breast Cancer Res Treat 2015; 151: 281-294.

Oncogenesis is an open-access journal published by Nature Publishing Group. This work is licensed under a Creative Commons Attribution 4.0 International License. The images or other third party material in this article are included in the article's Creative Commons license, unless indicated otherwise in the credit line; if the material is not included under the Creative Commons license, users will need to obtain permission from the license holder to reproduce the material. To view a copy of this license, visit http://creativecommons.org/licenses/by/4.0/

(c) The Author(s) 2017 